\title{
Biomedical Applications of Functionalized Carbon Nanotubes
}

\author{
Shivani Balyan ${ }^{1}$ and Rohit Bhatia ${ }^{2 *}$ \\ ${ }^{1}$ Department of Biochemistry, Institute of Home Economics, India \\ ${ }^{2}$ Division of Sustainable Technology, Rudraksh Prodhyogiki Sangathan, India
}

Submission: June 29, 2017; Published: July 25, 2017

*Corresponding author: Rohit Bhatia, Division of Sustainable Technology, Rudraksh Prodhyogiki Sangathan, India, Email: Bhatia.rohit10@gmail.com

\section{Abstract}

The carbon nanotubes (CNTs) are one of the most widely studied allotropes of carbon. Due to their high surface area and special structural, electrical and mechanical properties, they find application in the field of biomedical materials. But their large scale commercial application is hindered due their poor solubility in common solvents. However, the covalent and non-covalent functionalization of CNTs helps overcome this drawback by enhancing the solubility. These functionalized CNTs are used for various biomedical applications such as delivery of chemotherapeutic agents, gene delivery, bio-imaging, tissue engineering and muscle regeneration.

Keywords: Carbon Nanotube; Bio-imaging; Gene Delivery; Tissue Engineering

Abbreviations: CNT: Carbon Nanotubes; SWCNTs:Single Wall Nanotubes; MWCNTs: Multi Wall Nanotubes

\section{Introduction}

The element carbon is ubiquitous and is intimately connected with life on earth. Its allotropes, graphite and diamond are well known. Graphite conducts both heat and electricity but diamondone of the hardest materials known is non-conducting. In recent years, other allotropic forms of carbon have been discovered. These include fullerenes, carbon nanotubes and graphene, which play an important role in the field of nanotechnology.

Carbon Nanotubes (CNT) are the graphitic sheets which have covalently bonded carbon atoms in hexagonal-type arrangement. These sheets are rolled up into a form of cylinder with the ends closed by hemispherical graphitic domes. Due to their exceptional 1-D nature, CNTs are amongst the strongest materials known and possess special structural, electrical and mechanical properties. These have found applications in areas like batteries, fuel cells, pharmaceuticals and biomedical materials [1].

CNTs can be classified into two types,

o Single Wall Nanotubes (SWCNTs) and

o Multi Wall Nanotubes (MWCNTs)
SWCNTs are formed by rolling of a single layer of graphene having a typical diameter in the range of $0.4-2 \mathrm{~nm}$. There is no limitation, however, to the length of the graphene layer. On the other hand, MWCNTs which form due to the rolling up of several layers of graphene in coaxial arrangements have external diameter ranging from 10 to $100 \mathrm{~nm}$.

CNTs have found application in a number of areas such as drug delivery, optoelectronics and field effect transistor and recently in the area of organic photovoltaic's [2-5]. However, large scale commercial applications of CNTs are still lacking, which could be attributed to their poor solubility in most solvents. Chemical functionalization of CNTs does help overcome this drawback by enhancing their solubility. Chemical functionalization of SWCNTs can be classified into two major types:

o Non-covalent and

o $\quad$ Covalent approach [5]

The covalent functionalization of CNTs can be achieved by either:

o Functionalization of oxidized CNTs or 


\section{Global Journal of Nanomedicine}

o Functionalization of CNTs through addition reactions.

SWCNTs on treatment with strong acids such as concentrated nitric and sulphuric acid or subjecting them to highly oxidative conditions, like boiling in a mixture of sulfuric acid and hydrogen peroxide results in the formation of carbonyl, carboxyl and hydroxyl functionalities. The carboxylic acid generated on the side wall can be used for the functionalization of SWCNTs. Smalley and co-workers were the first to derivatize SWCNTs. They first reacted the carboxylic acid containing SWCNTs with thionyl chloride and then reacted it with long chain amines to form the amide bond the functionalized product being characterized using AFM microscopy [6]. Using the same approach SWCNTs were functionalized with octadecylamine to enhance their solubility in common organic solvents [7]. The functionalization of CNTs can also be achieved by addition reaction by reacting them with highly reactive species like nitrene, carbenes, azomethine ylide, aryl diazonium salts and bingel reaction [8-10].

\section{Biomedical Application of Functionalized CNTs}

Functionalized CNTs are reported to serve as materials for bone scaffolds, coating materials and drug delivery agents to support bone regeneration due to their strong mechanical properties, flexibility and high surface area. The functionalized CNTs shows high conductivity profiles, which lead to enhancement of the healing process. It has been reported that activity, adhesion and proliferation of osteoblast can be modified by external electrical stimulus. CNTs, due to their great conductivity, charge carrier mobility and tensile strength are considered as a potential material for bone regeneration [11]. The CNTs/polycarbonate urethane composite enhances the alkaline phosphates activity, calcium deposition, and osteoblast cell adhesion [12].

The functionalized CNTs have also been reported to act as a delivery agent for chemotherapeutic agents. The chemotherapeutic agents form strong $\pi-\pi$ interactions with functionalized CNTs which can be overcome by changing physical parameters like $\mathrm{pH}$ which then allows specific delivery of chemotherapeutic agents to targeted cells. Theoretically, functionalized CNTs have been shown to possess remarkable ability to absorb hydrophobic chemotherapeutic agents. The functionalized CNTs decorated with iron nanoparticles have been used for the delivery of chelerythrine [13]. The functionalized CNTs are also reported to be used in photodynamic therapy wherein they bring about a rise in temperature up to $60{ }^{\circ} \mathrm{C}$ thereby eliminating cancerous cells without damaging the surrounding tissues [14].

Functionalized CNTs due to their conductive, fibrous, hollow structure, and high surface to volume ratios, have been used for neural regeneration studies. The CNTs functionalized with silk materials was shown to enhance the neural differentiation and axonal lengths of human embryonic stem cells. The functionalized CNTs due to their electro active nature are found suitable for regeneration of cardiac muscles. The functionalized CNTs have been reported to enhance cardiomyocyte proliferation.

The CNTs functionalized with fluorescent functional groups or dyes have been used as contrasting agents for bioimaging applications. For example, CNTs functionalized with fluorescent dye FICT. The CNTs functionalized with gold and iron nanoparticles have been reported as PET imaging agent [15]. The functionalized CNTs have also been reported to function as a gene delivery agent and successfully deliver GFP gene in the cultured cell lines. They have also been used to successfully deliver SiRNA for gene silencing purpose in cultured cell lines.

\section{Conclusion}

The functionalized CNTs, due to their special properties and enhanced solubility in commonly used solvents, have found potential applications in the delivery of chemotherapeutics, biomedical imaging, tissue engineering and muscle regeneration. The CNTs can be functionalized using covalent or non-covalent methodology. The functionalization of CNTs with different biomolecules enhances their biocompatibility and decreases the cytotoxicity. These functionalized CNTs have been shown to act as effective gene delivery systems. Due to their versatile applications, functionalized CNTs will soon be the material of choice for scientists to develop next generation biomedical technologies ranging from drug delivery to bio-imaging.

\section{References}

1. Harris PJF (1999) Carbon Nanotubes and Related Structures: New Materials for the Twenty-first Century. Cambridge University Press, Great Britain.

2. Reich S, Thomsen C, Maultzsch J (2004) Carbon Nanotubes: Basic Concepts and Physical Properties. Wiley-VCH, Weinheim, Germany, pp. 224.

3. Kreupl F (2008) Carbon Nanotubes in Microelectronic Applications. Wiley-VCH, Verlag GmbH \& Co. Weinheim, Germany.

4. Cataldo F, Da Ros T (2008) Medicinal Chemistry and Pharmacological Potential of Fullerenes and Carbon Nanotubes. Springer-Verlag, Berlin, Heidelberg.

5. Guldi DM, Nazario Martin (2010) Carbon Nanotubes and Related Structures: Synthesis, Characterization, Functionalization and Applications. Wiley - $\mathrm{VCH}$, Verlag $\mathrm{GmbH} \&$ Co. KgaA, Weinheim, Germany.

6. Liu J, Rinzler AG, Dai H, Hafner JH, Bradley RK, et al. (1998) Fullerene pipes. Science 280(5367): 1253-1256.

7. Chen J, Hamon MA, Hu H, Chen Y, Rao AM, et al. (1998) Solution properties of single-walled carbon nanotubes. Science 282(5386): 9598.

8. Liang F, Sadana AK, Peera A, Chattopadhyay J, Gu Z, et al. (2004) Synthesis of water-soluble PEGylated single-walled carbon nanotubes. Nano Lett 18(5): 1257-1260.

9. Stephenson JJ, Sadana AK, Higginbotham AL, Tour JM (2006) Highly functionalized and soluble multiwalled carbon nanotubes by reductive alkylation and arylation. Chem Mater 18(19): 4658-4661.

10. Chattopadhyay J, Cortez de F, Chakraborty S, Slater NKH, Billups WE (2006) Synthesis of Water-Soluble PEGylated Single-Walled Carbon Nanotubes. Chem Mater 18(25): 5864-5868. 
11. Meng S, Ouabhia M, Zhang Z (2013) Electrical stimulation modulates osteoblast proliferation and bone protein production through heparinbioactivated conductive scaffolds. Bioelectromagnetics 34(3): 189199

12. Wickham AM, Islam MM, Mondal D, Phopase J, Sadhu V, et al. (2014) Polycaprolactone-thiophene-conjugated carbon nanotube meshes as scaffolds for cardiac progenitor cells. J Biomed Mater Res B Appl Biomater 102(7): 1553-1561.

13. Cao L, Liang Y, Zhao F, Zhao X, Chen Z (2016) Chelerythrine and $\mathrm{Fe}_{3} \mathrm{O}_{4}$
Loaded Multi-Walled Carbon Nanotubes for Targeted Cancer Therapy. J Biomed Nanotechnol 12(6): 1312-22.

14. Han S, Kwon T, Um JE, Haam S, Kim WJ (2016) Highly Selective Photothermal Therapy by a Phenoxylated-Dextran-Functionalized Smart Carbon Nanotube Platform. Adv Healthc Mater 5(10): 11471156.

15. Liu Z, Tabakman S, Welsher K, Dai H (2009) Carbon nanotubes in biology and medicine: in vitro and in vivo detection, imaging and drug delivery. Nano Res 2(2): 85-120.

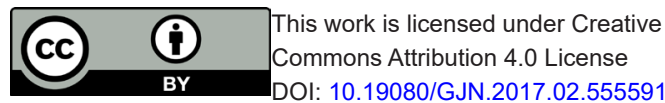

\section{Your next submission with JuniperPublishers will reach you the below assets}

- Quality Editorial service

- Swift Peer Review

- Reprints availability

- E-prints Service

- Manuscript Podcast for convenient understanding

- Global attainment for your research

- Manuscript accessibility in different formats ( Pdf, E-pub, Full Text, Audio)

- Unceasing customer service

Track the below URL for one-step submission https://juniperpublishers.com/submit-manuscript.php 